\title{
Application of Artificial Neural Networks to Project Reference Evapotranspiration under Climate Change Scenarios
}

Junaid Maqsood

University of Prince Edward Island

Aitazaz A. Farooque ( $\nabla$ afarooque@upei.ca )

University of Prince Edward Island

Farhat Abbas

University of Prince Edward Island

Travis Esau

Dalhousie University

Xander Wang

University of Prince Edward Island

Bishnu Acharya

University of Saskatchewan

Hassan Afzaal

University of Prince Edward Island

\section{Research Article}

Keywords: Artificial neural networks, General circulation model, Hargreaves method, Reference evapotranspiration, Statistical downscaling

Posted Date: July 12th, 2021

DOI: https://doi.org/10.21203/rs.3.rs-603225/v1

License: (c) (1) This work is licensed under a Creative Commons Attribution 4.0 International License.

Read Full License

Version of Record: A version of this preprint was published at Water Resources Management on January 13th, 2022. See the published version at https://doi.org/10.1007/s11269-021-02997-y. 


\section{Application of Artificial Neural Networks to Project Reference Evapotranspiration under \\ Climate Change Scenarios}

3 Junaid Maqsood ${ }^{1}$, Aitazaz A. Farooque ${ }^{1,2,}$, , Farhat Abbas ${ }^{2}$, Travis Esau ${ }^{3}$, Xander Wang ${ }^{2}$,

4 Bishnu Acharya ${ }^{4}$, and Hassan Afzaal ${ }^{1}$

$5{ }^{1}$ Faculty of Sustainable Design Engineering, University of Prince Edward Island, Charlottetown,

$6 \quad$ PE C1A 4P3, Canada

$7{ }^{2}$ School of Climate Change and Adaptation, University of Prince Edward Island, Charlottetown, $8 \quad$ PE C1A 4P3, Canada

93 Engineering Department, Dalhousie University, Agriculture Campus, Truro, NS B2N 5E3, $10 \quad$ Canada

114 Department of Chemical and Biological Engineering, University of Saskatchewan, Saskatoon, 12 SK S7N 5A9, Canada

13 *Correspondence: afarroque@ upei.ca [A.A.F.], Ph: (902) 5666084

14

15 Abstract: Evapotranspiration, one of the major elements of the water cycle, is sensitive to climate 16 change. The main objective of this study was to examine the response of reference 17 evapotranspiration $\left(\mathrm{ET}_{0}\right)$ under various climate change scenarios using artificial neural networks 18 and a general circulation model (GCM) - the Canadian Earth System Model Second Generation

19 (CanESM2). The Hargreaves method was used to calculate $\mathrm{ET}_{0}$ for western, central, and eastern

20 parts of Prince Edward Island. The two input parameters of the Hargreaves method; daily 21 maximum temperature (Tmax), and daily minimum temperature (Tmin) were projected using

22 CanESM2. The Tmax and Tmin were downscaled with the help of statistical downscaling and 23 simulation model (SDSM) for three future periods 2020s (2011-2040), 2050s (2041-2070), and 
24 2080s (2071-2100) under three representative concentration pathways (RCP's) including RCP 2.6,

25 RCP P4.5, and RCP 8.5, and the. Temporally, there were major changes in Tmax, Tmin, and ET 0

26 for the 2080s under RCP8.5. The temporal variations in $\mathrm{ET}_{0}$ for all RCPs matched the reports in

27 the literature for other similar locations and for RCP8.5 it ranged from 1.63 (2020s) to 2.29

$28 \mathrm{~mm} /$ day (2080s). As a next step, a one-dimensional convolutional neural network (1D-CNN),

29 long-short term memory (LSTM), and multilayer perceptron (MLP) were used for estimating $\mathrm{ET}_{0}$

30 due to the non-linear behavior of $\mathrm{ET}_{0}$ and the limited meteorological input data. High coefficient

31 of correlation $(r>0.95)$ values for both calibration and validation periods showed the potential of

32 the artificial neural networks in $\mathrm{ET}_{0}$ estimation. The results of this study will help decision makers

33 and water resource managers to quantify the availability of water in future for the island and to

34 optimize the use of island water resources on a sustainable basis.

35 Keywords: Artificial neural networks; General circulation model; Hargreaves method; Reference 36 evapotranspiration; Statistical downscaling

\section{$37 \quad 1 \quad$ Introduction}

Atmospheric increase of greenhouse gases from excessive use of the fossil fuels and human

39 interventions have caused global warming (Huang et al. 2011). Atmospheric temperature is rising

40 in numerous parts of the world (Abbas et al. 2018; Shi et al. 2020; Shafiq et al. 2019) included

41 Canada (Zhai et al. 2019). All sectors of life like, agriculture, water resources, ecosystem, and

42 human health have been badly affected due to climate variability globally (Abbas et al. 2018;

43 Maqsood et al. 2020). Therefore, investigating and understanding future climate variability at a

44 site-specific/regional scale is necessary to adapt, mitigate these changes.

It is imperative to analyze the effect of climate variability on the water cycle.

46 Evapotranspiration (ET) is an essential element of the water cycle and consists of two processes: 
47 evaporation (from the soil), and transpiration (from the plant leaves). Evapotranspiration from the

48 reference crop surface is known as Reference evapotranspiration $\left(\mathrm{ET}_{0}\right)$. A comprehensive

49 definition of ET and its components can be found in Allen et al. (1998). Accurate measurement of

$50 \mathrm{ET}_{0}$ is required for irrigation scheduling, water resources management, designing agricultural

51 practices, and hydrological studies. Many empirical methods are used to measure ET that is used

52 to estimate $\mathrm{ET}_{0}$ (Almorox et al. 2015).

The Penman-Monteith method can accurately measure $\mathrm{ET}_{0}$ in various climate conditions.

54 It requires various climatic parameters like temperature, sunshine hours, wind speed, and vapor

55 pressure for calculating $\mathrm{ET}_{0}$ (Allen et al. 1998). However, this method challenging in many parts

56 of the world due to the non-availability of the meteorological and climatic parameters data.

57 Especially for future projection of $\mathrm{ET}_{0}$ the downscaling of the input climatic parameters is not

58 reliable (Randall et al. 2007), which also limits, its use. Therefore, temperature based empirical

59 methods may be preferred for $\mathrm{ET}_{0}$ estimation to overcome these limitations. Temperature data are

60 easily accessible for almost all the world's meteorological stations and its projection by the

61 available GCMs is more reliable than any other climatic parameters (Randall et al. 2007). Vicente-

62 Serrano et al. (2014) stated that the Hargreaves method can be used as a quality method for

63 estimating the $\mathrm{ET}_{0}$ if input data for the Penman-Monteith method is not available. Numerous

64 studies have compared the results of the Hargreaves method and standard Penman-Monteith

65 method and reported that the first method performed well in both cold and arid climates (Almorox

66 et al. 2015; Ren et al. 2016).

67 The outputs of the GCMs under different RCPs prescribed by the intergovernmental panel

68 on climate change may only be used on a global or continental level (Wilby et al. 2000). Therefore,

69 the outputs of the GCMs cannot present a credible view on the local/site-specific scale due to 
70 parameterization limitations. Hence, useful dynamic and statistical downscaling techniques have

71 been used to make the GCMs outputs useful at a local/site-specific scale.

72 Statistical downscaling technique offers immediate outputs of climate variables

73 (precipitation and temperature) and is much simpler, cheaper and flexible than the dynamic

74 technique (Zhang et al. 2020; Wilby et al. 2000). Empirical/statistical relationships between large-

75 scale atmospheric predictors (e.g., surface mean temperature, surface precipitation, etc.) and local

76 scale parameters (e.g., observed precipitation and temperature) have been established in this

77 technique by using multiple linear regression (MLR). There exist various statistical downscaling

78 models, but the SDSM has been selected for this study as it is most accurate and widely used to

79 downscale and project the climate variables (Arshad et al. 2019; Birara et al. 2020). Wilby et al.

80 (2002) presented a comprehensive review of SDSM to assess the regional climate change impacts.

81 The non-linear nature of $\mathrm{ET}_{0}$ because of its contributing meteorological parameters

82 (Landeras et al. 2008) requires non-linear problem-solving techniques for its accurate estimation.

83 Artificial neural network techniques (ANNs) have a non-linear mathematical structure which is

84 very useful in modeling complex non-linear problems (Sudheer et al. 2003). Hashemi and

85 Sepaskhah (2020) estimated ET 0 with the Penman-Monteith method and ANNs namely MLP and

86 the radial basis function (RBF) and reported that both the ANNs performed well as compared to

87 the Penman-Monteith method. Zanetti et al. (2007) used MLP and RBF for estimating $\mathrm{ET}_{0}$ from

88 Tmax, Tmin, and/or different neural network architecture and found that MLP gave better results,

89 with a single hidden layer, 10 neurons, and activation function type of hyperbolic tangent sigmoid,

90 than RBF.

91 Long short-term memory has a chain-like structure that is capable of storing previous

92 information and can also handle time series problems (Zhang et al. 2018). Afzaal et al. (2020a) 
93 estimated $\mathrm{ET}_{0}$ by using the recurrent neural networks (RNNs) namely LSTM and bidirectional

94 LSTM and a limited number of meteorological parameters. They reported the high accuracy of

95 these networks in estimating $\mathrm{ET}_{0}$. Majhi et al. (2020) used different combinations of

96 meteorological parameters for computing the $\mathrm{ET}_{0}$ and compared the results of LSTM with MLP

97 and empirical methods (Hargreaves and Blaney-Criddle). They found that LSTM can estimate $\mathrm{ET}_{0}$

98 with higher accuracy as compared to the other models. One-dimensional convolutional neural

99 networks (1D-CNNs) are deep learning algorithms mostly used to analyzing visual imagery. These

100 networks are the most advanced forms of the ANNs as they have more hidden layers as compared

101 to the MLP and LSTM. These networks can also be used in time series problems if they are

102 modeled properly (Ferreira and da Cunha 2020).

103 Evapotranspiration is not only the major climatic component that controls the water

104 balance, but it is a major component that controlled the production of a crop. The variation in $\mathrm{ET}_{0}$

105 may create problems especially in those areas, where most of the agricultural lands are rainfed

106 such as Atlantic Canada. Future projections of $\mathrm{ET}_{0}$ can help to make irrigation strategies for rainfed

107 areas where the temperature is expected to increase, and rainfall may vary due to climate change.

108 Future projections of $\mathrm{ET}_{0}$ for Prince Edward Island, an important agricultural province of Atlantic

109 Canada, have not yet been conducted and/or reported in the literature. The main reason might be

110 the non-availability of the required climatic parameters for the calculation of $\mathrm{ET}_{0}$. Therefore, the

111 main objective of this study was to predict ET $_{0}$ with the use of ANNs and a Canada-specific GCM

112 (CanESM2).

\section{Materials and methods}

\section{$114 \quad 2.1$ Description of the study area}


116 (Statistics Canada 2020). It covers approximately $5660 \mathrm{~km}^{2}$ geographical area and is $225 \mathrm{~km}$ long

117 and 3-65 km wide at its various transects. It is located between 62 to $64{ }^{\circ} \mathrm{W}$ longitude and 46 to

$11847^{\circ} \mathrm{N}$ latitude. The climate of the province is humid continental and affected by the surrounding

119 Northumberland Strait seas and the Gulf of Saint Lawrence. The summer season is moderately 120 warm, and occasionally its Tmax reaches as high as $34^{\circ} \mathrm{C}$ (Government of PEI 2015). The densely 121 planted crops on the island are potatoes, grains, and oilseeds (barley, oats, wheat, canola, corn, and 122 soybean), fruits (blueberries, cranberries, strawberries, grapes, and apple), vegetables (carrot, 123 cabbage, cucumber, tomatoes, onion, and cauliflower) (Government of PEI 2020).

124

125

126

127

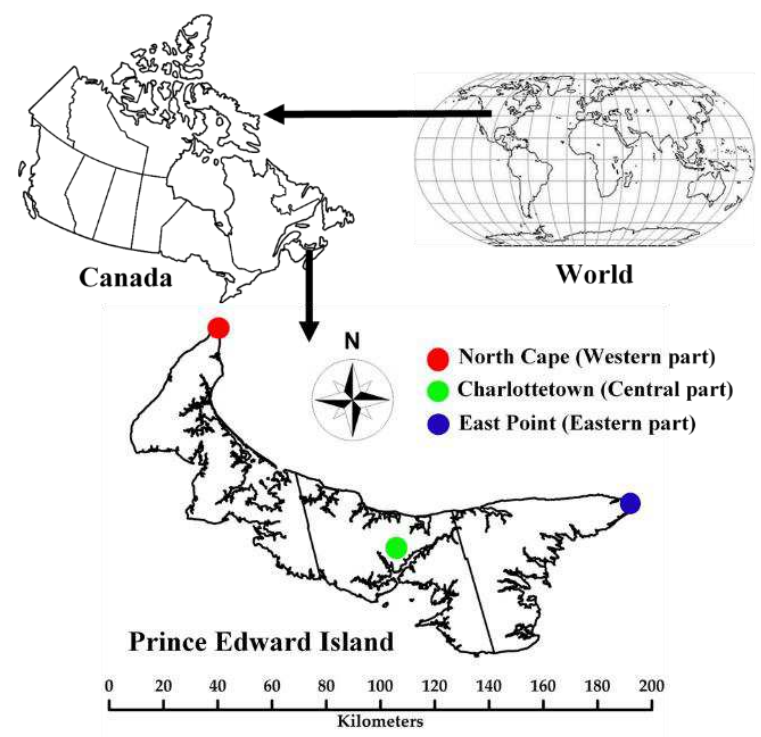

Fig.1 location map meteorological stations situated in Prince Edward Island used for this study.

\subsection{Data sources and analysis activities}

Meteorological data (Tmax and Tmin) on daily basis, GCM data (CanESM2), and National Center of Environmental Prediction/National Center for Atmospheric Research (NCEP/NCAR) data were used in this study. The study objective was achieved by using the above data and through i. investigating the ability of the SDSM to downscale and assess the variation in Tmax and Tmin 
132 for three future periods the 2020s, 2050s, and 2080s, ii. calculating $\mathrm{ET}_{0}$ in baseline (1989-2005)

133 and future three-time periods using limited meteorological data (Tmax and Tmin) in Hargreaves

134 method, and iii. estimating the non-linear $\mathrm{ET}_{0}$ with the help of artificial neural networks (MLP,

135 LSTM, and CNN) for baseline and future periods.

\subsubsection{Meteorological data}

Three meteorological stations, namely North Cape, Charlottetown, and East Point were

138 selected to assess the temperature and $\mathrm{ET}_{0}$ changes in the study area (Figure 1, Table 1). The

139 selection of these stations was based on the data quality, different locations on the island, and the

140 length of the available daily data (1989-2005). The daily Tmax and Tmin for the baseline period

141 were collected from Environmental Canada (Government of Canada 2017). These datasets were

142 used as a predictand in calibration and validation of the SDSM.

143 Table 1 The attributes of the selected meteorological stations in Prince Edward Island, Canada.

\begin{tabular}{lcccccc}
\hline Stations & $\begin{array}{c}\text { Latitude } \\
\left({ }^{\circ}\right)\end{array}$ & $\begin{array}{c}\text { Longitude } \\
\left({ }^{\circ}\right)\end{array}$ & $\begin{array}{c}\text { Elevation } \\
(\mathbf{m})\end{array}$ & $\begin{array}{c}\text { Up.Thr. } \\
\mathbf{T m a x}\left({ }^{\circ} \mathbf{C}\right)\end{array}$ & $\begin{array}{c}\text { Lo.Thr. } \\
\text { Tmin }\left({ }^{\circ} \mathbf{C}\right)\end{array}$ & Data missing $(\%)$ \\
\hline North Cape & 47.06 & -64.00 & 7.60 & 33.2 & -33.0 & 1.68 \\
Charlottetown & 46.23 & -63.17 & 13.7 & 33.0 & -29.8 & 0.64 \\
East Point & 46.46 & -61.99 & 7.70 & 33.5 & -31.0 & 0.77 \\
\hline
\end{tabular}

Up.Thr.Tmax: Upper threshold value of daily maximum temperature; Lo.Thr.Tmin.: Lower threshold value of daily minimum temperature.

145 The missing values of data were estimated using relevant neighboring station $\left(\mathrm{R}^{2}>0.90\right)$

146 data and adopting a linear regression model. The linear regression model was used to create a

147 relation between target and neighboring stations which helped in estimating the missing values

148 between the observed data.

$149 \quad$ 2.2.2 The general circulation model data

150 The GCM model used in this study was CanESM2 developed by the Canadian Centre for

151 Climate Modeling and Analysis (CCCma) of Environment Canada. The CanESM2 model outputs 
152 between 2006 to 2100 were retrieved for three different climate scenarios RCPs of 2.6 (low forcing

153 scenario),4.5 (medium stabilization scenario), and 8.5 (very high emission scenarios). These

154 scenarios are defined under the future projection of greenhouse gas emissions, and possible ranges

155 of radiative forcing values of $2.6,4.5$, and $8.5 \mathrm{~W} / \mathrm{m}^{2}$ as well as $\mathrm{CO}_{2}$ concentrations of 420, 540,

156 and $940 \mathrm{mg} / \mathrm{L}$ in the 2100 year, respectively (van Vuuren et al. 2011). Moreover, CanESM2 has

157 been reported to perform well with the SDSM in downscaling Tmax and Tmin as compared to 158 other GCMs (Birara et al. 2020; Hassan and Hashim 2020). It also covers the study area with a 159 relatively higher spatial grid resolution of $2.8125^{\circ} \times 2.8125^{\circ}$. It has been widely and most used

160 GCM in climate change impact studies (lotfi et al. 2020; Shafiq et al. 2019)

161 Besides CanESM2 model outputs for three different climate scenarios, large-scale 162 atmospheric variables from NCEP/NCAR were utilized for creating a statistical relationship with 163 the historical Tmax and Tmin. CCCma also provides the NCEP/NCAR predictors for the (1961164 2005) period. Both CanESM2 and NCEP/NCAR data have the same set of 26 predictors' variables 165 (Table 2). Two tiles (Box_106X_49Y and Box_107X_49Y) of CanESM2 cover the study area. 166 The data of these two tiles were retrieved from the Canadian climate data and scenarios website 167 (Government of Canada 2019) and then processed by the SDSM to predict Tmax and Tmin for the 168 future periods. The SDSM performed well in the projections of local climate variability (Al169 Mukhtar and Qasim 2019; Birara et al. 2020).

170 Table 2 The List of 26 predictors of NCEP

\begin{tabular}{cccc}
\hline No. & Predictors & No. & Predictors \\
\hline 1 & Surface precipitation (ncepprcpgl) & 14 & Vorticity at Surface (ncepp1_zgl) \\
2 & Surface specific humidity (ncepshumgl) & 15 & Vorticity at $500 \mathrm{hPa}\left(\mathrm{ncepp5 \_ zgl)}\right.$ \\
3 & Mean sea level pressure (nceppmslpgl) & 16 & Vorticity at $850 \mathrm{hPa}$ (ncepp8_zgl) \\
4 & Surface mean temperature (nceptempgl) & 17 & Wind direction at Surface (ncepp1thgl) \\
\hline
\end{tabular}




\begin{tabular}{|c|c|c|c|}
\hline 5 & Air flow strength at surface (ncepp1_fgl) & 18 & Wind direction at $500 \mathrm{hPa}$ (ncepp5thgl) \\
\hline 6 & Air flow strength at $500 \mathrm{hPa}$ (ncepp5_fgl) & 19 & Wind direction at $850 \mathrm{hPa}$ (ncepp8thgl) \\
\hline 7 & Air flow strength at $850 \mathrm{hPa}$ (ncepp8_fgl) & 20 & Divergence at Surface (ncepp1zhgl) \\
\hline 8 & Zonal velocity at surface (ncepp1_ugl) & 21 & Divergence at $500 \mathrm{hPa}$ (ncepp5zhgl) \\
\hline 9 & Zonal velocity at $500 \mathrm{hPa}$ (ncepp5_ugl) & 22 & Divergence at $850 \mathrm{hPa}$ (ncepp8zhgl) \\
\hline 10 & Zonal velocity at $850 \mathrm{hPa}$ (ncepp8_ugl) & 23 & Geopotential height at $500 \mathrm{hPa}($ ncepp $500 \mathrm{gl})$ \\
\hline 11 & Meridional velocity at surface (ncepp1_vgl) & 24 & Specific humidity at $500 \mathrm{hPa}($ nceps $500 \mathrm{gl})$ \\
\hline 12 & Meridional velocity at $500 \mathrm{hPa}$ (ncepp5_vgl) & 25 & Geopotential height at $850 \mathrm{hPa}($ ncepp $850 \mathrm{gl})$ \\
\hline 13 & Meridional velocity at $850 \mathrm{hPa}$ (ncepp8_vgl) & 26 & Specific humidity at $850 \mathrm{hPa}$ (nceps $850 \mathrm{gl})$ \\
\hline
\end{tabular}

$172 \quad 2.3$ Description of Statistical downscaling and simulation model

173 The SDSM was developed by Wilby et al. (2002). It is a hybrid model of MLR and

174 stochastic weather generator (SWG). The MLR creates an empirical/statistical relationship

175 between the predictand (Tmax and Tmin) and NCEP predictors (large scale parameters) which

176 produce regression parameters from the input data. These calibrated parameters of MLR are used

177 in SWG to generate time series data up to 100 years. The detail of getting outputs is described in

178 (Wilby et al. 2002). The steps for downscaling GCM data included 1. quality control analysis, 2.

179 screening of the predictors, 3. model calibration, 4. generation of weather, 5. model validation, 6.

180 scenario generation using GCM data.

181 Quality control deals with filling in missing values present in a dataset and replace the 182 missing values with code -999 as per model provisions.

183 Screening of the NCEP predictors is a crucial and most important step for all the statistical

184 downscaling methods as these predictors highly influence the output of the SDSM (Huang et al. 185 2011). Partial correlation, p-value, and correlation matrix are mostly used in combination for the 
screening of the predictors (Huang et al. 2011; Wilby et al. 2002). The steps described by

Mahmood and Babel (2013) were used for the screening of NCEP predictors:

First, NCEP predictors were extracted for the baseline period (1989-2005) for better correlation results. The procedure adopted for the screening of NCEP predictors for Tmax at the central part of the island is shown in Table 3. A correlation matrix was computed between

191 predictand (Tmax and Tmin) and the 26 NCEP predictors. Predictors that have the highest 192 correlation ( $\left.R \_1\right)$ in this matrix with the predictand (12 in this case) were separated and arranged 193 in descending order. The first NCEP predictor that has (R_1) value was selected and called a super 194 predictor (SP). The predictor nceptemp was the SP for Tmax at the central part of the island as it 195 had the highest correlation (0.93) with the predictand.

196 Table 3 Procedure adopted in the screening of NCEP predictors for Tmax at the central part of the island.

\begin{tabular}{ccccccc}
\hline Sr & NCEP Predictors & R_1 (\%) & R_2 (\%) & p.r (\%) & p-value & PRP \\
\hline $\mathbf{1}$ & nceptempgl & $\mathbf{0 . 9 3}$ & & & & \\
2 & ncepp500gl & 0.87 & 0.85 & 0.37 & 0.00 & 0.57 \\
3 & ncepshumgl & 0.86 & 0.92 & 0.05 & 0.00 & 0.95 \\
4 & nceps850gl & 0.71 & 0.76 & 0.03 & 0.06 & 1.04 \\
5 & ncepp850gl & 0.63 & 0.58 & 0.21 & 0.00 & 1.33 \\
6 & nceps500gl & 0.47 & 0.52 & 0.17 & 0.00 & 1.37 \\
$\mathbf{7}$ & ncepp1_vgl & $\mathbf{0 . 4 4}$ & $\mathbf{0 . 3 6}$ & $\mathbf{0 . 3 8}$ & $\mathbf{0 . 0 0}$ & $\mathbf{0 . 1 3}$ \\
8 & ncepp5_fgl & 0.35 & 0.31 & 0.02 & 0.20 & 0.95 \\
9 & ncepp5_zgl & 0.36 & 0.31 & 0.25 & 0.00 & 1.70 \\
10 & ncepp8_zgl & -0.29 & 0.19 & 0.22 & 0.00 & 1.75 \\
11 & ncepp5_ugl & 0.26 & 0.23 & 0.07 & 0.00 & 0.73 \\
12 & ncepp1_fgl & 0.24 & 0.21 & 0.08 & 0.00 & 0.66 \\
\hline
\end{tabular}
correlation between predictand and predictors and in the presence of SP; PRP: Percentage reduction in partial correlation to the correlation coefficient. Bold values were the screened predictor for Tmax at Charlottetown station.

After finding the SP, the correlation coefficient between the remaining selected NCEP

201 predictors (11 in this case) and predictand (R_1), correlation coefficient among NCEP predictors 202 (R_2), partial correlation (p.r), and p-value were calculated in the presence of SP. The predictors 203 having a high correlation (R_2) coefficient with the SP (0.5 in this study) were eliminated to 
204 minimize the multicollinearity between predictors. The $\mathrm{R} \_2$ between two predictors up to 0.7 is 205 acceptable (Pallant, 2007). In this study, the predictors (ncepp500gl, ncepshumgl, nceps850gl, 206 ncepp850gl, and nceps500gl) had the highest correlation (R_2 >0.5) with the SP and were 207 eliminated from the list to minimize multi co-linearity. Then, the predictors having a high p-value $208>0.05$ were also eliminated to keep the results statistically significant. So, ncepp5_fgl and 209 nceps850gl were also eliminated from the list as they had a p-value higher than 0.05 .

210 The percentage of reduction in partial correlation to the correlation coefficient (PRP) was used to

211 find the second most appropriate NCEP predictor and was calculated by the following equation.

$$
\mathrm{PRP}=\frac{\rho \cdot \mathrm{r}-\mathrm{R} \_1}{\mathrm{R} \_1}
$$

213 where, $\mathrm{R} \_1$ is correlation coefficient, and $\rho . \mathrm{r}$ is the partial correlation between predictand and 214 predictors.

A predictor with the lowest PRP value was selected as the second most suitable predictor

216 and it had very low multi co-linearity with the SP. The predictor ncepp1_vgl was selected as the 217 second-most appropriate predictor for Tmax at the central part of the island as it had the lowest 218 PRP value (0.13) and it did not have a strong correlation with the SP. The next predictors were 219 selected by repeating these steps.

\subsubsection{Model calibration, validation, and future scenarios generation}

The complete dataset of the baseline period (1989-2005) with screened NCEP predictors 222 was split into 70\% for calibration (1989 to 2000) and 30\% for validation (2001-2005). The options 223 of ordinary least square (OLS), unconditional and monthly sub-models were chosen in the model 224 interface for calibration purposes. Validation was carried out with the output of the calibration run. 225 Then, 20 ensembles of synthetic daily future weather series had been generated by SWG. The 
226 average of these 20 daily ensembles had been compared with the historical data for the validation

227 period. The calibrated model was used to project Tmax and Tmin for the future period 2006-2100

228 under different RCPs $(2.6,4.5,8.5)$. The pattern of climatic variables was modeled for three future

229 periods namely the 2020s, 2050s, and 2080s.

\section{$230 \quad 2.4$ Hargreaves method}

Various methods are used for predicting the $\mathrm{ET}_{0}$ but the Penman-Monteith method is the

232 standard and most precise method to estimate the $\mathrm{ET}_{0}$. It required various weather parameters such

233 as temperature, moisture content, wind velocity, and solar radiation. Many meteorological stations

234 do not have a complete dataset of the meteorological parameters and the required data set mostly

235 unavailable. So, alternate $\mathrm{ET}_{0}$ methods like Hargreaves, Blaney-Criddle, FAO-56 reduced set, and

236 Turc methods are used which required only a few meteorological parameters. It was found from

237 previous studies that the Hargreaves method was performed well in predicting the $\mathrm{ET}_{0}$ as compared

238 to other $\mathrm{ET}_{0}$ methods like BC, FA0-56 reduced method (Fisher and Pringle 2013; Hafeez et al.

239 2020). That's why, Hargreaves method was used in this study due to its accuracy over other

240 methods and non-availability of the required dataset, and non-reliability of downscaling and

241 projecting the meteorological parameters required for the Penman-Monteith method.

242 The Hargreaves method was used to estimate the $\mathrm{ET}_{0}$ from Tmax and Tmin data

243 (Hargreaves and Samani 1985). The equation used in this method is:

244

$$
\mathrm{ET}_{0}=0.408(0.0023)(17.8+\mathrm{Tmean})(\mathrm{Tmax}-\mathrm{Tmin})^{0.5} \mathrm{R}_{\mathrm{a}}
$$

245 where $\mathrm{R}_{\mathrm{a}}$ is extraterrestrial radiation $\left(\mathrm{MJm}^{-2}\right)$ and 0.408 is an empirical factor to convert $\mathrm{MJm}^{-2}$ to $246 \mathrm{~mm}$. 
247 The solar radiation at the top of the earth's atmosphere is used as $R_{a}$. Its values range from $\sim 12$ to

$248 \sim 31 \mathrm{MJm}^{-2}$ in PEI with winter months reflecting the lower values and vice versa. It is calculated,

249 based on the latitude of the location and the calendar day of the year, by the given equation:

$250 \quad \mathrm{R}_{\mathrm{a}}=\frac{24(60)}{\pi} \times \mathrm{G}_{\mathrm{sc}}\left(\mathrm{d}_{\mathrm{r}}\right)\left[\left(\sin (\varphi) \times \omega_{\mathrm{s}} \times \sin (\delta)\right)+\left(\cos (\varphi) \times \cos \left(\omega_{\mathrm{s}}\right) \times \cos (\delta)\right)\right]$

251 where, $\mathrm{G}_{\mathrm{sc}}$ is the solar constant $\left(0.0820 \mathrm{MJm}^{-2}\right)$. The value of $\mathrm{G}_{\mathrm{sc}}$ showed the amount of solar 252 energy per unit time, at the mean distance of the earth from the sun, received on a unit area of a 253 surface normal to the sun outside the atmosphere. In equation 3, $\varphi$ is the latitude of the location 254 (radians). Latitudes for North Centre, Charlottetown, and East Point locations were used as 0.8214, $2550.8079,0.8109$ radians. Similarly, $d_{r}$ is the inverse relative distance from the earth to the sun and 256 calculated based on the calendar day of the year as:

$$
\mathrm{d}_{\mathrm{r}}=1+\left[0.33 \times \cos \left(\frac{2 \pi}{365} \mathrm{~J}\right)\right]
$$

258 where $\mathrm{J}$ is the calendar day of the year.

259 In equation $3, \omega_{\mathrm{s}}$ represents the sunset hour angle (radians). Its values range from $\sim 1$ to $\sim 2$ radians

260 in Prince Edward Island with winter months reflecting the lower values and vice versa. It is 261 calculated as:

$$
\omega_{\mathrm{s}}=\arccos (-\tan (\varphi) \times \tan (\delta))
$$

263 where, $\delta=$ solar declination (radians), and is calculated as:

$$
\left.\delta=0.409 \times \sin \left(\left(\frac{2 \pi}{365} \times \mathrm{J}\right)-1.39\right)\right)
$$

265 Its values range from $\sim-0.4$ to $\sim 0.4$ radians in Prince Edward Island with winter months reflecting 266 negative values and vice versa. 


\section{$268 \quad 2.5$ Deep learning algorithms}

269 Three artificial neural networks (1D-CNN, LSTM, and MLP) were used to estimate the 270 daily $\mathrm{ET}_{0}$ for baseline (1989-2005) and future periods (the 2020s, 2050s, and 2080s) under three

271 RCPs for western, central, and eastern parts of the island. The ANNs were trained by using $70 \%$

272 of data in each period under every RCP and validated by the remaining $30 \%$ of data at all the parts

273 of the island. The hyperparameters (learning rate, optimizer, and batch size) were found by the

274 trial-and-error method. Learning rate (1.r) is a configurable hyperparameter that controls how 275 quickly the model is adapted to the problem and it has small positive values (0 to 1.0). Batch size

276 is the hyperparameter that refers to the number of samples used in one iteration. The most used

277 batch sizes are 32,64, and 128. Optimizers are the methods that reduced the losses by changing the 278 attributes (learning rates or weights) of the neural network. The highest performing combination 279 of the learning rate, optimizer, and batch size was used for calibration and validation of the 280 networks (Afzaal et al. 2020b). It was found that in this study CNN and MLP performed well at 281 learning rate $=0.01$, batch size $=64$, and optimizer $=$ Adam, while LSTM performed well at batch 282 size $=128$ and with the same learning rate and optimizer as CNN and MLP. The network's 283 estimated $\mathrm{ET}_{0}$ values were compared with the Hargreaves method output $\left(\mathrm{ET}_{0}\right)$ by naming it as 284 the actual $\mathrm{ET}_{0}$. The main reason for adopting these networks was the non-linear behavior of the $285 \mathrm{ET}_{0}$ and limited meteorological data availability. 


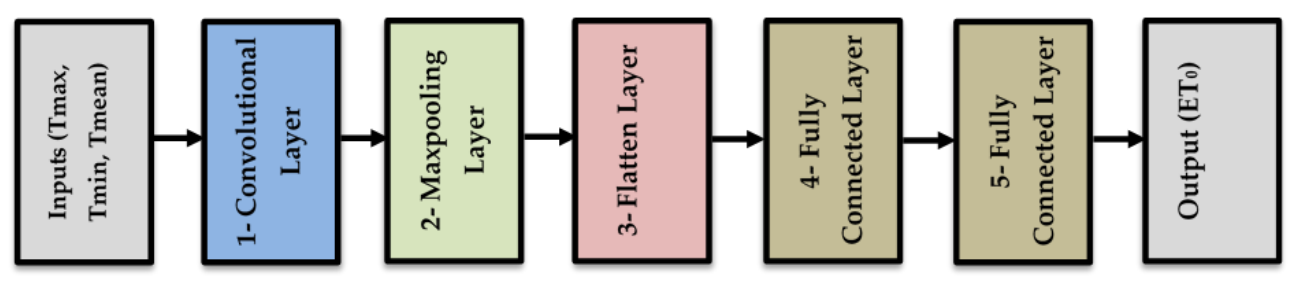

(a)

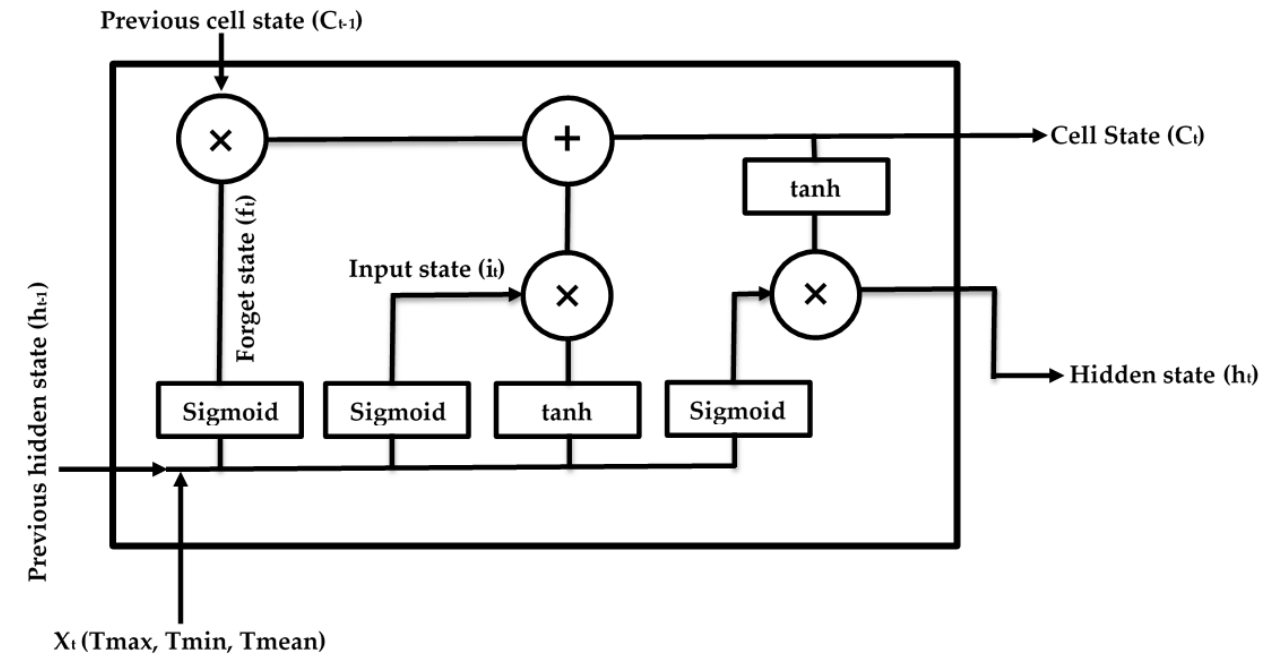

(b)

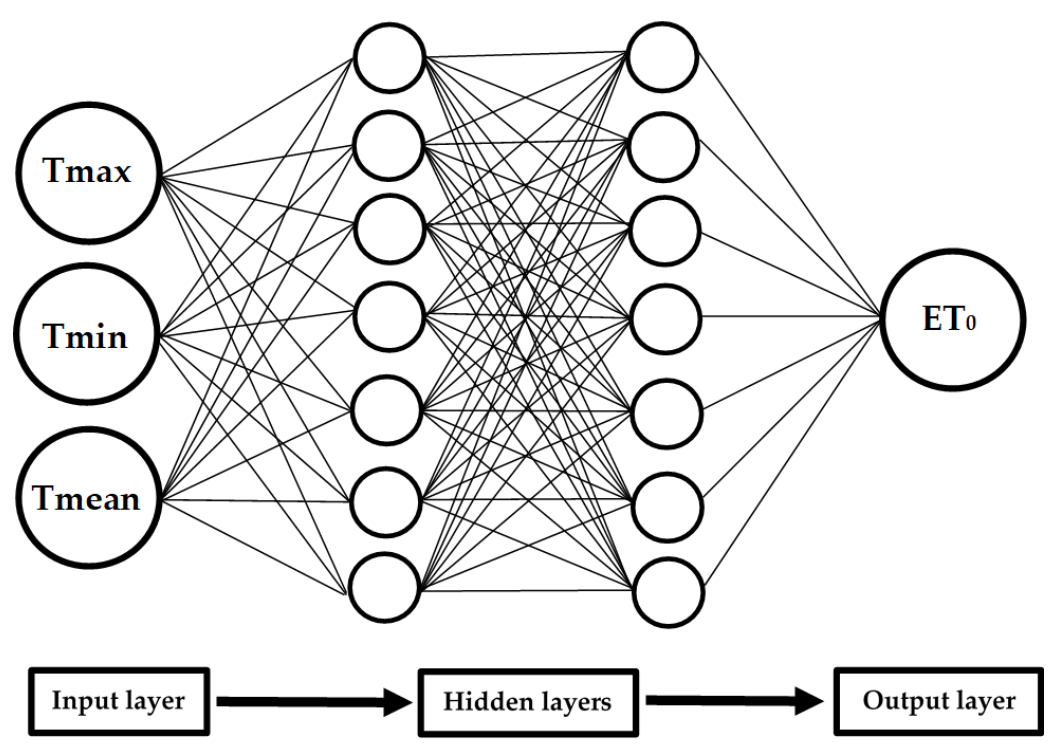

(c)

Fig.2 (a) Block diagram of the one-dimensional convolutional neural network; (b) memory block of the long-short term memory network, and (c) Structure of multilayer perceptron neural network. 
Convolutional Neural Networks are mostly used for two-dimensional (2D) images in

291 machine vision applications while 1D-CNN has many applications in natural language processing

292 and time series classification problems. Five layers were used in this study followed by appropriate

293 hyperparameter selection by the hit-and-miss method (Figure 2a). The first layer was the

294 convolutional layer which takes input (Tmax, Tmin, and Tmean). This layer connects with a max-

295 pooling layer to extract the features. The third (flatten) layer was used to join the max-pooling and 296 last two fully connected layers.

The LSTM is a form of recurrent neural network $(\mathrm{RNN})$ that predicts time series problems.

298 It's a sequence-based model that can store the previous information and relate it to a sequence for

299 predicting the time series. Longer sequences cannot be saved in RNNs due to the problem of 300 gradient vanishing in the early layers. The gradient vanishing problem is due to short-term 301 memory. RNNs have chain like composition which helps the data to flow from them. RNNs store 302 the information, based on the time or sequence steps, as a hidden state $\left(h_{t}\right)$ at every stage. i.e., $h_{t}$ 303 for every input $\left(\mathrm{X}_{\mathrm{t}}\right)$. Hyperbolic tangent function (tanh) also presents in the structure of the RNN 304 that scales the input date from -1 to 1 . The problems of short-term memory of the RNN are solved 305 by adding more states into its memory.

The temporal and sequel dependence of the previous blocks retained by adding the forget

307 state $\left(\mathrm{f}_{\mathrm{t}}\right)$ and cell state $\left(\mathrm{C}_{\mathrm{t}}\right)$ in LSTM. The $\mathrm{f}_{\mathrm{t}}$ of LSTM keeps or discards the information, and it 308 depends on the output values of the sigmoid function. Those values which are closer to 1 are kept 309 while the closer values to 0 are discarded. The previous hidden state $\left(\mathrm{h}_{\mathrm{t}-1}\right)$ and $\mathrm{X}_{\mathrm{t}}$ processed and 310 giving out a new input ( $\left.\mathrm{i}_{t}\right)$ using the sigmoid activation function. The $\mathrm{i}_{t}$ is also given in the range 311 of 1 to 0 without ignoring any information like $f_{t} . C_{t}$ is calculated by adding the $f_{t}$ and the dot 
312 product of the sigmoid and tanh functions. The detailed review of information flow in the LSTM

313 memory block is shown in Figure 2b.

314 An MLP is a common type of feedforward artificial neural network, which is mostly used

315 in hydrology and water resources problems for modeling non-linear processes (Afzaal et al.

316 2020b). In this study, it was used for estimating the $\mathrm{ET}_{0}$. It contains multiple layers including

317 input, hidden, and output layers (Figure 2c). Neurons are the fundamental processing unit of the

318 ANNS that connect all these layers. The input layer takes all the variables like Tmax, Tmean, and

319 Tmin for the prediction of output i.e., $\mathrm{ET}_{0}$. The hidden layers added the inputs and used an

320 activation function for creating the output. The most common activation functions are sigmoid,

321 tanh, and rectified linear unit. A rectified linear unit was used in this study due to its better

322 performance relative to others.

323 In this study, 100 neurons and two hidden layers were selected by the trial-and-error

324 method. A comparison of different learning algorithm was used in many studies and Levenberg-

325 Marquardt was reported to be faster and had higher accuracy relative to the other algorithm (Kisi

326 and Demir 2016; Tabari and Hosseinzadeh Talaee 2013). Therefore, the Levenberg-Marquardt

327 learning algorithm was chosen for this study to find out the loss function due to its best 328 performance.

\section{$329 \quad 2.6$ Statistical evaluator}

330 Two statistical evaluators, coefficient of correlation (r) and root mean square error 331 (RMSE), were used for assessing the performance of the SDSM and the machine learning 332 algorithms as suggested and used by Afzaal et al. (2020a) and Al-Mukhtar and Qasim (2019).

333 Closure the value of $r$ to ' 1 ' showed the better performance of the model. 


$$
r=\frac{\sum_{i=1}^{N}(y i-\bar{y})^{2}-\sum_{i=1}^{N}(y i-\hat{y} i)^{2}}{\sqrt{\sum_{1=1}^{N}(y i-\bar{y})^{2}}}
$$

335 The RMSE, an error index, is used to calculate the differences between the observed and predicted 336 data. Closure the value of RMSE to ' 0 ' showed the better performance of the model.

$$
\text { RMSE }=\sqrt{\frac{\sum_{\mathrm{i}=1}^{\mathrm{N}}(\mathrm{yi}-\hat{\mathrm{y} i})^{2}}{\mathrm{~N}}}
$$

338 where yi is the estimated value at the ith time; yi is the actual value at the ith time; $\bar{y}=$ mean value

339 of the yi; $\mathrm{N}=$ number of values and $\mathrm{i}$ ranges from 1 to $\mathrm{N}$.

\section{$340 \quad 3$ Results and discussion}

\section{$341 \quad 3.1$ Predictors selection}

342 The screened NCEP predictors for Tmax were nceptemp and ncepp1_v, while nceptemp and 343 ncepp5_z were the screened predictors for Tmin at all the parts of the island. It was observed that 344 the nceptemp was the SP for both Tmax and Tmin variables at all the parts of the island. The 345 nceptemp was also found as SP in different studies (Arshad et al. 2019; Mahmood and Babel 346 2013). These screened predictors of Tmax and Tmin were used for calibrating the SDSM.

\section{$347 \quad 3.2$ Evaluation, calibration, and validation of SDSM}

The selected predictors of NCEP were used for the calibration and validation period of the

349 SDSM. The results of Tmax and Tmin simulated by SDSM were compared with the observed

350 values for calibration (1989-2000) and validation (2001-2005) period. The simulated results of

351 both Tmax and Tmin variables at all the parts of the island had a high correlation with their

352 respective observed Tmax and Tmin during the calibration and validation periods. The values of $r$

353 for Tmax and Tmin at all the parts of the island were greater than 0.95 . The simulated results of 
354 the Tmax and Tmin were in a better agreement with the observed mean monthly values and can

355 be observed in visual presentation (Figure 3) where simulated results during the validation period

356 were very near to the observed values at all the parts of the island. It indicated the better efficiency

357 of the SDSM in simulating the Tmax and Tmin, its reliability, and applicability of the model in

358 Prince Edward Island, Canada for climate change prediction.
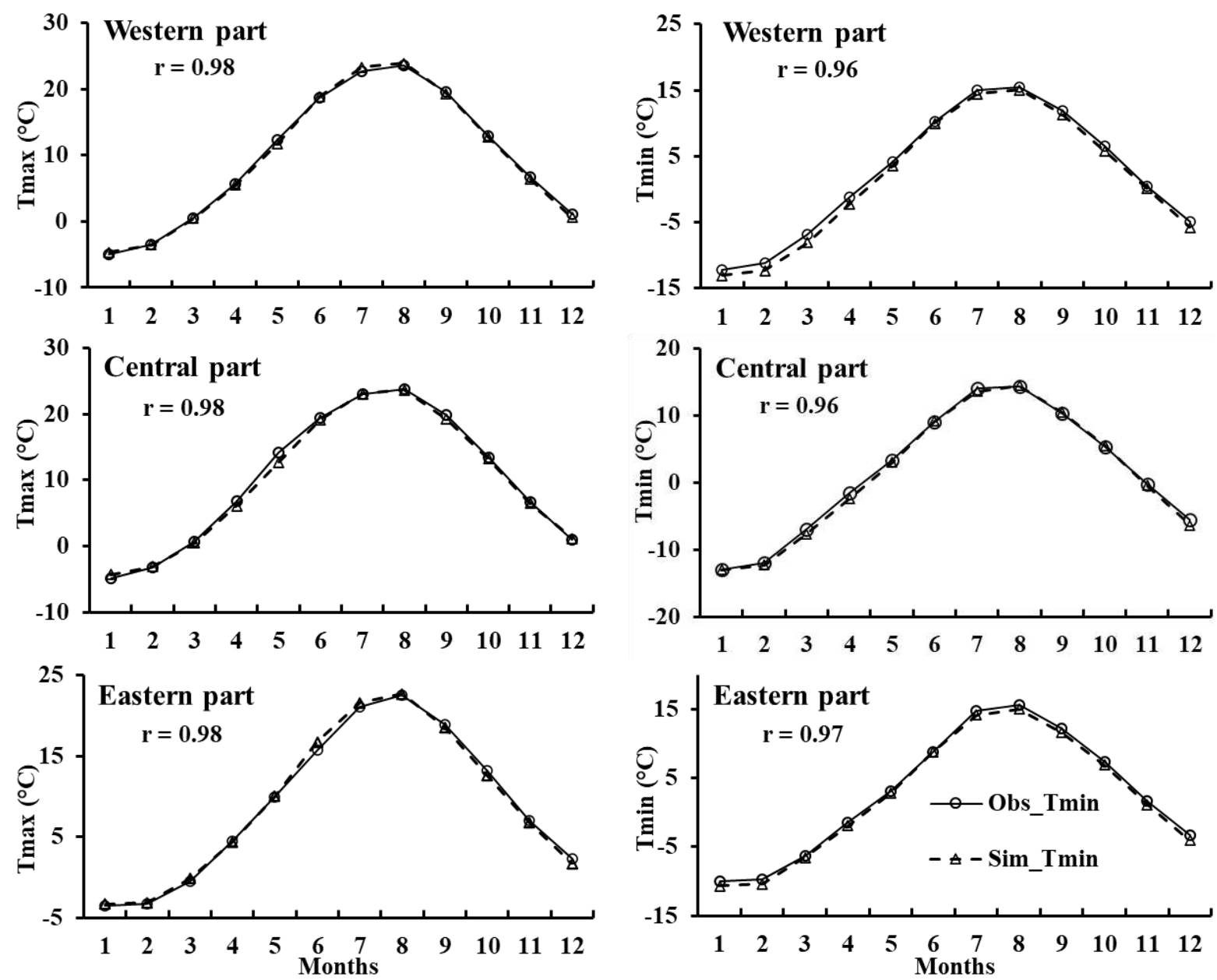

Fig. 3 Comparison between observed and simulated mean monthly Tmax (daily maximum temperature) and Tmin (daily minimum temperature) during the validation period (2001-2005).

\subsection{Change of climate factors under different future climate scenarios}

364 Tmax and Tmin for the 2006-2100 period. The projected Tmax and Tmin were used in the 
365 Hargreaves method for calculating the $\mathrm{ET}_{0}$. These variations in average annual Tmax, Tmin, and $366 \mathrm{ET}_{0}$ were illustrated in Figure 4 for the baseline and future periods (2020s, 2050s, and 2080s) 367 based on the RCPs (2.6, 4.5, and 8.5) for western, central, eastern parts of the island. The middle 368 line of the boxes in Figure 4 shows the median value, while the lower and upper boundaries of the 369 boxes indicate $25 \%$ and $75 \%$ of the data sets, respectively. The lower and upper whiskers show 370 the $10^{\text {th }}$ and $90^{\text {th }}$ percentiles, respectively. Results presented in these figures showed an increment 371 in the future average annual Tmax, Tmin, and $\mathrm{ET}_{0}$ irrespective of the RCPs and parts of the island.

372 RCP2.6 showed less change in the average annual values of Tmax, Tmin, and $\mathrm{ET}_{0}$ as 373 compared to RCP4.5 and RCP 8.5 at all the parts of the island. The increment in the average annual 374 values of Tmax, Tmin, and $\mathrm{ET}_{0}$ became larger as the time increased into the future periods. RCP8.5 375 showed maximum variations of $\mathrm{Tmax}, \mathrm{Tmin}$, and $\mathrm{ET}_{0}$ in future periods. 

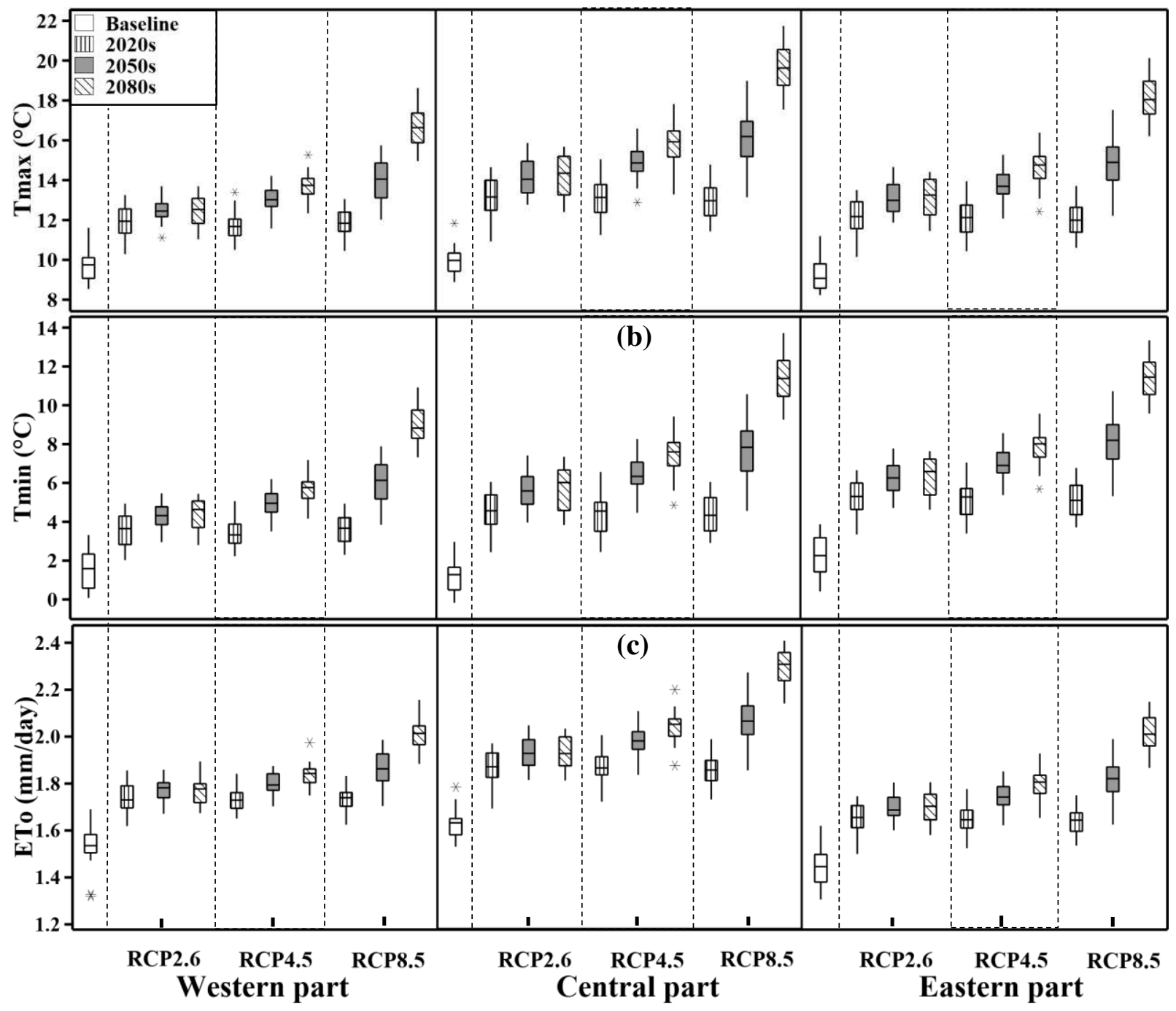

Fig. 4 Projected changes in the average annual $\operatorname{Tmax}\left({ }^{\circ} \mathrm{C}\right), \mathrm{Tmin}\left({ }^{\circ} \mathrm{C}\right)$, and $\mathrm{ET}_{0}(\mathrm{~mm} /$ day) for baseline $(1989-2005)$ and future periods the 2020s (2011-2040), 2050s (2041-2070), and 2080s (2071-2100) at western, central, eastern parts of the island under different RCPs $(2.6,4.5$, and 8.5$)$. The (*) asterisk symbol represents the presence of outliers in the data.

A larger average annual increment in Tmax, Tmin, $\mathrm{ET}_{0}$ was found under RCP 8.5 in all the parts as compared to the RCP 4.5 and RCP 2.6 in future periods. The projected change in the average annual Tmax was approximately varied from 11.74 (2020s) to 16.55 (2080s) at the western part, $12.86(2020 \mathrm{~s})$ to $19.52(2080 \mathrm{~s})$ at the central part, and $11.93(2020 \mathrm{~s})$ to $18.02^{\circ} \mathrm{C}(2080 \mathrm{~s})$ at the eastern part of the island under RCP8.5. The variation in the average annual Tmin was observed from $3.53(2020 \mathrm{~s})$ to $8.90(2080 \mathrm{~s})$ at the western part, $4.50(2020 \mathrm{~s})$ to $11.33(2080 \mathrm{~s})$ at the central 
part, $5.21(2020 \mathrm{~s})$ to $11.36^{\circ} \mathrm{C}(2080 \mathrm{~s})$ at the eastern part of the island under RCP8.5. The calculated average annual $\mathrm{ET}_{0}$ changed in the range of 1.64 (2020s) to 1.92 (2080s), 1.64 (2020s) to 2.03 (2080s), and $1.63(2020 \mathrm{~s})$ to $2.29 \mathrm{~mm} /$ day (2080s) at all the parts of the island under RCP2.6, RCP4.5, and RCP8.5 respectively. and Daigle (2011) predicted that the Tmax and Tmin values are likely to increase in the future

394 periods for Prince Edward Island. Shi et al. (2020) projected the $\mathrm{ET}_{0}$, Tmax, and Tmin in 395 southeastern Australia, and reported that the changes in these parameters were increased over time 396 and maximum changes were observed under RCP8.5. Lotfi et al. (2020) used outputs of the 397 CanESM2 model under RCP2.6, 4.5, and 8.5 to find the effect of climate variability on the $\mathrm{ET}_{0}$ in 398 the West of Iran by calculating the $\mathrm{ET}_{0}$ by Hargreaves and Priestley-Taylor methods and observed 399 the highest rate of change of $\mathrm{ET}_{0}$ was under RCP8.5 scenarios.

\subsection{Deep learning algorithms based evaluations}

401 All the models were run at the selected combination for all the baseline and future periods and 402 found out the validation $r$, and RMSE (Table 4). The changes in r values were observed at western 403 part which were 0.96 to 0.98 (CNN), 0.96 to 0.97 (LSTM), and 0.96 to 0.98 (MLP) while at central 404 part r values were changed from 0.96-0.97, 0.96, and 0.96 to 0.97 for CNN, LSTM, and MLP, 405 respectively. The values of $\mathrm{r}$ in the eastern part were also changed, irrespective of the RCPs and 406 periods, from 0.95 to $0.98,0.95$ to 0.97 , and 0.95 to $0.98 \%$. The CNN, LSTM, and MLP validation

407 RMSE were recorded in the range of $0.28-0.30,0.29-0.31$, and $0.28-0.29 \mathrm{~mm} /$ day respectively in 408 the western part. The validation RMSE values for the central part were recorded in the range of $409 \quad 0.30-0.36,0.30-0.38$, and $0.30-0.34 \mathrm{~mm} /$ day, while for the eastern part it was recorded in the range 410 of $0.26-0.27,0.28-0.31$, and $0.26-0.27 \mathrm{~mm} /$ day for CNN, LSTM, and MLP, respectively. The 
411 results of $\mathrm{r}$ and RMSE showed that all these neural networks performed well in calculating the $\mathrm{ET}_{0}$

412 but CNN and MLP both showed slightly higher accuracy at all the parts of the as compared to the

413 LSTM. The validation $r$ and RMSE at all the parts of the island showed slightly higher accuracy

414 (r) in the 2080s scenario under RCP8.5 (Figure 5).

415 Table 4 The RMSE and $r$ for the validation periods of artificial neural networks (CNN, LSTM, and MLP) for western, 416 central, and eastern parts of the island.

\begin{tabular}{|c|c|c|c|c|c|c|c|c|}
\hline \multirow{2}{*}{$\begin{array}{c}\text { Parts of } \\
\text { the } \\
\text { island }\end{array}$} & \multirow[b]{2}{*}{ RCPs } & \multirow[b]{2}{*}{$\begin{array}{c}\text { Future } \\
\text { Scenarios }\end{array}$} & \multicolumn{2}{|c|}{$\mathrm{CNN}$} & \multicolumn{2}{|c|}{ LSTM } & \multicolumn{2}{|c|}{ MLP } \\
\hline & & & $\begin{array}{c}\text { Valid_ } \\
\mathbf{r}\end{array}$ & $\begin{array}{l}\text { Valid_ } \\
\text { RMSE }\end{array}$ & $\begin{array}{c}\text { Valid_ } \\
\mathbf{r}\end{array}$ & $\begin{array}{l}\text { Valid_ } \\
\text { RMSE }\end{array}$ & $\begin{array}{c}\text { Valid_ } \\
\mathbf{r}\end{array}$ & $\begin{array}{l}\text { Valid_ } \\
\text { RMSE }\end{array}$ \\
\hline \multirow{10}{*}{$\begin{array}{l}5 \\
\frac{0}{0} \\
3 \\
3\end{array}$} & Baseline & $\begin{array}{l}1989- \\
2005 \\
\end{array}$ & 0.96 & 0.29 & 0.96 & 0.30 & 0.96 & 0.29 \\
\hline & \multirow{3}{*}{$\mathrm{RCP} 2.6$} & $2020 \mathrm{~s}$ & 0.97 & 0.28 & 0.97 & 0.29 & 0.97 & 0.28 \\
\hline & & $2050 \mathrm{~s}$ & 0.97 & 0.29 & 0.97 & 0.3 & 0.97 & 0.28 \\
\hline & & $2080 \mathrm{~s}$ & 0.97 & 0.28 & 0.97 & 0.29 & 0.97 & 0.29 \\
\hline & \multirow{3}{*}{$\mathrm{RCP} 4.5$} & $2020 \mathrm{~s}$ & 0.97 & 0.29 & 0.96 & 0.3 & 0.97 & 0.28 \\
\hline & & $2050 \mathrm{~s}$ & 0.97 & 0.29 & 0.97 & 0.3 & 0.97 & 0.28 \\
\hline & & $2080 \mathrm{~s}$ & 0.97 & 0.29 & 0.97 & 0.3 & 0.97 & 0.28 \\
\hline & \multirow{3}{*}{ RCP8.5 } & $2020 \mathrm{~s}$ & 0.97 & 0.28 & 0.96 & 0.3 & 0.97 & 0.28 \\
\hline & & $2050 \mathrm{~s}$ & 0.97 & 0.29 & 0.97 & 0.31 & 0.97 & 0.28 \\
\hline & & $2080 \mathrm{~s}$ & 0.98 & 0.3 & 0.97 & 0.32 & 0.98 & 0.29 \\
\hline \multirow{10}{*}{ 苛 } & Baseline & $\begin{array}{l}1989- \\
2005\end{array}$ & 0.96 & 0.30 & 0.96 & 0.30 & 0.96 & 0.30 \\
\hline & \multirow{3}{*}{$\mathrm{RCP} 2.6$} & $2020 \mathrm{~s}$ & 0.97 & 0.3 & 0.96 & 0.32 & 0.96 & 0.31 \\
\hline & & $2050 \mathrm{~s}$ & 0.96 & 0.32 & 0.96 & 0.33 & 0.96 & 0.31 \\
\hline & & $2080 \mathrm{~s}$ & 0.96 & 0.31 & 0.96 & 0.32 & 0.96 & 0.32 \\
\hline & \multirow{3}{*}{ RCP4.5 } & $2020 \mathrm{~s}$ & 0.96 & 0.32 & 0.96 & 0.33 & 0.96 & 0.23 \\
\hline & & $2050 \mathrm{~s}$ & 0.96 & 0.32 & 0.96 & 0.34 & 0.96 & 0.32 \\
\hline & & $2080 \mathrm{~s}$ & 0.96 & 0.32 & 0.96 & 0.34 & 0.96 & 0.32 \\
\hline & \multirow{3}{*}{ RCP8.5 } & $2020 \mathrm{~s}$ & 0.96 & 0.3 & 0.96 & 0.32 & 0.96 & 0.3 \\
\hline & & $2050 \mathrm{~s}$ & 0.97 & 0.34 & 0.96 & 0.35 & 0.97 & 0.33 \\
\hline & & $2080 \mathrm{~s}$ & 0.97 & 0.36 & 0.96 & 0.38 & 0.97 & 0.34 \\
\hline \multirow{6}{*}{ 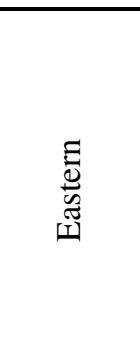 } & Baseline & $\begin{array}{l}1989- \\
2005\end{array}$ & 0.95 & 0.27 & 0.95 & 0.28 & 0.95 & 0.27 \\
\hline & \multirow{3}{*}{$\mathrm{RCP} 2.6$} & $2020 \mathrm{~s}$ & 0.97 & 0.26 & 0.96 & 0.28 & 0.97 & 0.26 \\
\hline & & $2050 \mathrm{~s}$ & 0.97 & 0.27 & 0.96 & 0.28 & 0.97 & 0.26 \\
\hline & & $2080 \mathrm{~s}$ & 0.97 & 0.26 & 0.96 & 0.28 & 0.97 & 0.27 \\
\hline & \multirow{2}{*}{$\mathrm{RCP} 4.5$} & $2020 \mathrm{~s}$ & 0.97 & 0.27 & 0.96 & 0.29 & 0.96 & 0.26 \\
\hline & & $2050 \mathrm{~s}$ & 0.97 & 0.26 & 0.96 & 0.29 & 0.97 & 0.26 \\
\hline
\end{tabular}




\begin{tabular}{cccccccc} 
& $2080 \mathrm{~s}$ & 0.97 & 0.26 & 0.96 & 0.29 & 0.97 & 0.27 \\
\hline \multirow{3}{*}{ RCP8.5 } & $2020 \mathrm{~s}$ & 0.96 & 0.27 & 0.96 & 0.29 & 0.96 & 0.26 \\
& $2050 \mathrm{~s}$ & 0.97 & 0.27 & 0.97 & 0.29 & 0.97 & 0.27 \\
& $2080 \mathrm{~s}$ & 0.98 & 0.27 & 0.97 & 0.31 & 0.98 & 0.27 \\
\hline
\end{tabular}

CNN: convolutional neural network; LSTM: long-short term memory; MLP: multilayer perceptron; r: coefficient of correlation; RMSE: root means

418 square error

419 The lower peaks in figures $5 \mathrm{a}, \mathrm{b}, \mathrm{c}$ indicate the $\mathrm{ET}_{0}$ in the winter season of the year while

420 higher peaks reflect the values of $\mathrm{ET}_{0}$ for the summer season. The results of this study corroborate

421 with other studies in which MLP, and CNN performed well as compared to other deep learning

422 models. Ferreira and da Cunha (2020) used deep learning algorithms (combination of CNN and

423 LSTM, and LSTM, 1D CNN), and outdated machine learning models (artificial neural network

424 and random forest) for forecasting (seven days) of the daily $\mathrm{ET}_{0}$. They found that the deep learning

425 algorithms showed slightly better performance as compared to the traditional machine learning

426 models and can be used for forecasting the $\mathrm{ET}_{0}$. Tabari and Hosseinzadeh Talaee (2013) used four

427 MLP models for estimating the $\mathrm{ET}_{0}$ in the semi-arid region of Iran. They used a different

428 combination of meteorological variables in these models and concluded that the MLP model can

429 be used for calculating the $\mathrm{ET}_{0}$. The results also showed that all these neural networks that have a

430 non-linear structure can be used for predicting the $\mathrm{ET}_{0}$ by using minimal meteorological data. 

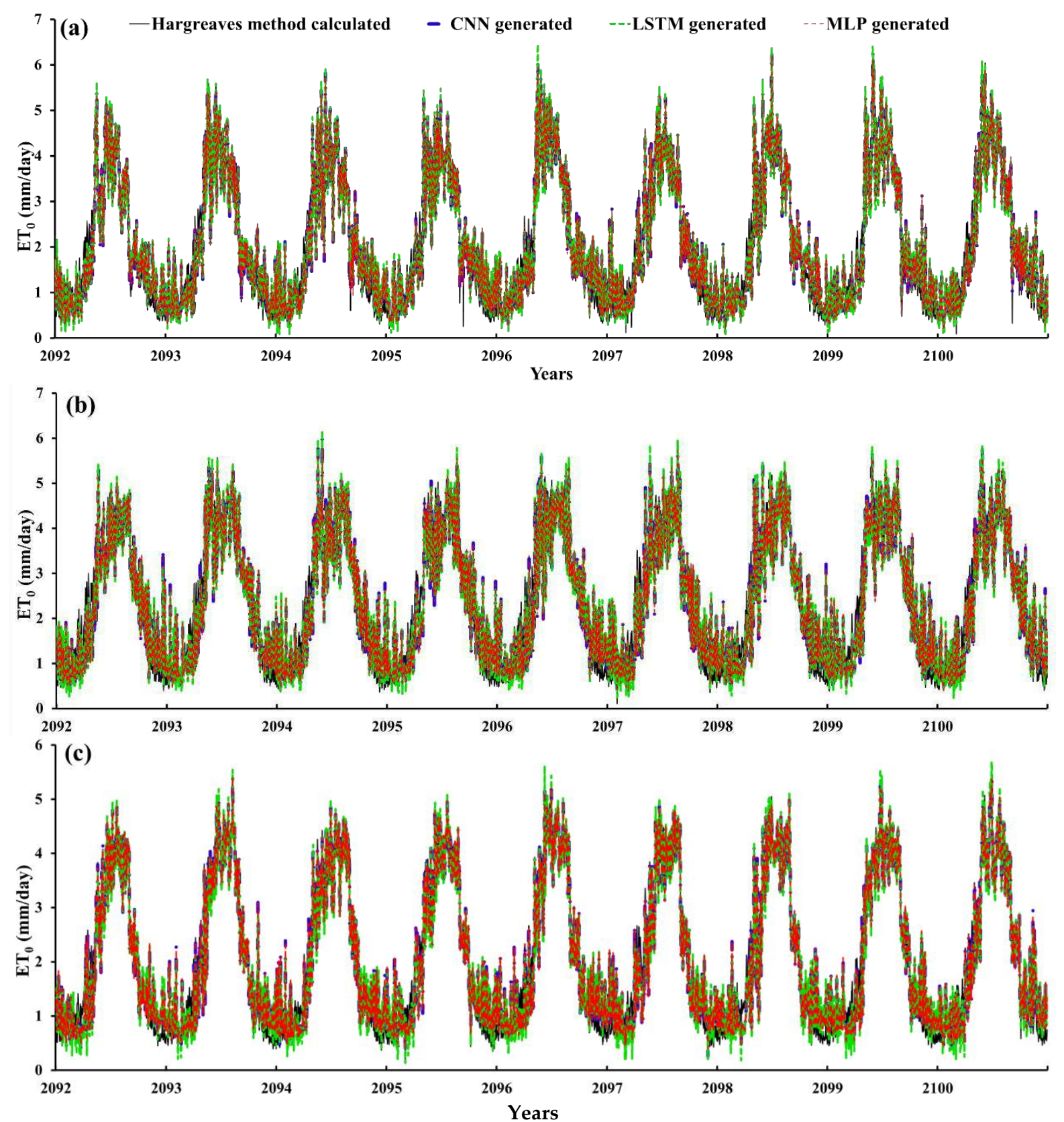

431

432

433

\section{4}

Fig. 5 Validation phase of 2080s time span under RCP8.5 for CNN, LSTM, and MLP at (a) western part, (b) central part, (c) eastern part of Prince Edward Island.

\section{Conclusion}

This study deals with the change in the patterns of climatic parameters (Tmax, Tmin, and $\left.\mathrm{ET}_{0}\right)$ in the baseline (1989-2005) and future (2006-2100) periods. These projected results were

437 compared with the baseline period. The comparison results showed that the projection of Tmax, 
438 Tmin, and $\mathrm{ET}_{0}$ for all the parts of the island were different in magnitude but similar in the pattern

439 under all the three RCPs. The temporal variation showed that changes in Tmax, Tmin, and $\mathrm{ET}_{0}$

440 were exceeded over time under all the RCPs. Overall, it was noticed that, in all the cases of this

441 study, the highest and the worst changes in the considered climate variables were found in the

442 2080s under RCP8.5, as also reported in various studies.

443 All the models showed higher accuracy (>95\%) in estimating the $\mathrm{ET}_{0}$ for the three future

444 periods under all the RCPs in all the parts of the island. No major difference was observed in the

445 performance of the neural networks. The use of the new architecture of neural networks (LSTM

446 and $\mathrm{CNN}$ ) did not show any better performance as compared to the older one (MLP). It was

447 observed that CNN and MLP performed quite similarly and have almost the same accuracy, while

448 LSTM showed slightly lower accuracy as compared to them for estimating ET $_{0}$ for all the

449 scenarios. This study showed that all the models, SDSM (for downscaling of Tmax and Tmin),

450 Hargreaves method (for calculating the $\mathrm{ET}_{0}$ with limited input parameters), and ANNs (CNN,

451 LSTM, and MLP) for highly accurate estimation of the $\mathrm{ET}_{0}$ were applicable in this study area

452 (Prince Edward Island) of Canada. This study will also help in future management relating to water

453 resources, irrigation scheduling, supplement irrigation, and eco-environment management 454 practices.

455 The literature reviewed indicated that no work has been done so far for the generation of 456 future $\mathrm{ET}_{0}$ from statistically downscaled meteorological data (Tmax, Tmin, and Tmean) by using 457 the Hargreaves method and ANNs (1D-CNN, LSTM, and MLP) in Prince Edward Island, Canada. 458 This might be due to the inaccessibility to the meteorological stations, nonavailability of 459 meteorological data, and inadequate resources. This study may be a valuable benchmark for others 
460 who wants to apply these models and methods for accessing the variations in future Tmax, Tmin, 461 and $\mathrm{ET}_{0}$.

462 Acknowledgments: We would like to acknowledge the assistance and cooperation of the

463 Precision Agriculture Team of the University of Prince Edward Island during this study.

\section{Declarations}

465 Authors contribution: Conceptualization: Junaid Maqsood, Aitazaz A. Farooque, Farhat Abbas;

466 Methodology: Junaid Maqsood, Farhat Abbas; Formal analysis and investigation: Junaid 467 Maqsood, Farhat Abbas, Hassan Afzaal; Data curation: Junaid Maqsood, Travis Esau, Bishnu 468 Acharya, Hassan Afzaal; Validation: Aitazaz A. Farooque, Xander Wang, Travis Esau; Writing 469 original draft preparation: Junaid Maqsood, Aitazaz A. Farooque, Farhat Abbas; Writing - review 470 and editing: Xander Wang, Bishnu acharya; Project administration: Aitazaz A. Farooque, Farhat 471 Abbas; Funding acquisition: Aitazaz A. Farooque; Supervision: Aitazaz A. Farooque.

472 Funding: Natural Science and Engineering Research Council of Canada has supported this study.

473 Ethical approval: Not applicable.

474 Consent to participate and publish: All authors consent that they have voluntarily participated 475 in this study and give permission to publish it.

476 Competing interests/Conflict of interest: The authors declare that they do not have any conflict 477 of interest.

478 Availability of data, material, and code: All the data, material, and codes are saved and will be 479 available on request. 


\section{References}

483 Abbas F, Sarwar N, Ibrahim M, Adrees M, Ali S, Saleem F, Hammad H.M (2018b) Patterns 484 of climate extremes in the coastal and highland regions of Balochistan, Pakistan. Earth Interact 485 22: 1-23. https://doi.org/10.1175/EI-D-16-0028.1

486 Afzaal H, Farooque AA, Abbas F, Acharya B, Esau T (2020a) Computation of 487 evapotranspiration with artificial intelligence for precision water resource management. Appl. $488 \quad$ Sci $10: 1621$. https://doi.org/10.3390/app10051621

489 Afzaal H, Farooque AA, Abbas F, Acharya B, Esau T (2020b) Groundwater estimation from 490 major physical hydrology components using artificial neural networks and deep learning. 491 Water (Switzerland) 12: 5. https://doi.org/10.3390/w12010005

492 Al-Mukhtar M, Qasim M (2019) Future predictions of precipitation and temperature in Iraq 493 using the statistical downscaling model. Arab. J. Geosci 12: 1-16. 494 https://doi.org/10.1007/s12517-018-4187-x

495 Allen RG, Pereira LS, Raes D (1998) Crop evapotranspiration-Guidelines for computing crop 496 water requirements-FAO Irrigation and drainage paper 56. Fao, Rome.

497 Almorox J, Quej VH, Martí P (2015) Global performance ranking of temperature-based 498 approaches for evapotranspiration estimation considering Köppen climate classes. J. Hydrol 499 528: 514-522. https://doi.org/10.1016/j.jhydrol.2015.06.057

500 Arshad A, Zhang Z, Zhang W, Gujree I (2019) Long-term perspective changes in crop 501 irrigation requirement caused by climate and agriculture land use changes in rechna doab, $502 \quad$ Pakistan. Water 11, 1567. https://doi.org/10.3390/w11081567

503 Birara H, Pandey RP, Mishra SK (2020) Projections of future rainfall and temperature using 504 statistical downscaling techniques in Tana Basin, Ethiopia. Sustain. Water Resour. Manag 6: 
506 Ferreira LB, da Cunha FF (2020a) Multi-step ahead forecasting of daily reference 507 evapotranspiration using deep learning. Comput. Electron. Agric 178: 105728. 508 https://doi.org/10.1016/j.compag.2020.105728

509 Fisher DK, Pringle HC (2013) Evaluation of alternative methods for estimating reference 510 evapotranspiration. Agric. Sci 4: 51-60. https://doi.org/10.4236/as.2013.48a008

511 Government of Canada (2019) CanESM2 predictors: CMIP5 experiments. https://climate512 scenarios.canada.ca/?page=pred-canesm2. Accessed 11 Apr 2020

513 Government of Canada (2017) Station Results - Historical Data. 514 https://climate.weather.gc.ca/historical_data/search_historic_data_stations_e.html?searchTyp $515 \mathrm{e}=$ stnProv\&timeframe $=1 \& 1$ stProvince=PE\&optLimit=yearRange $\&$ StartYear $=1840 \&$ EndYea $516 \mathrm{r}=2020 \&$ Year=2020\&Month=11\&Day=3\&selRowPerPage=25. Accessed 11 Apr 2020

517 Government of Prince Edward Island (2015) PEI Climate and Weather. $518 \quad \underline{\text { https://www.princeedwardisland.ca/en/information/communities-land-and- }}$

519 environment/island-climate-and-weather. Accessed 23 Mar 2020

520 Government of Prince Edward Island (2020) Agriculture on PEI. 521 https://www.princeedwardisland.ca/en/information/agriculture-and-land/agriculture-pei.

$522 \quad$ Accessed 27 Feb 2021

523 Hafeez M, Chatha ZA, Khan AA, Bakhsh A, Basit A, Tahira F, Khan G (2020) Estimating 524 reference evapotranspiration by hargreaves and blaney-criddle methods in humid subtropical 525 conditions. Curr. Res. Agric. Sci 7: 15-22. https://doi.org/10.18488/journal.68.2020.71.15.22

526 Hargreaves G. H., Samani Z. A., 1985. Reference Crop Evapotranspiration from Temperature. 527 Appl. Eng. Agric. 1, 96-99. https://doi.org/10.13031/2013.26773 
529 Hashemi, M., Sepaskhah, A.R., 2020. Evaluation of artificial neural network and Penman

530 Monteith equation for the prediction of barley standard evapotranspiration in a semi-arid

531 region. Theor. Appl. Climatol. 139, 275-285. https://doi.org/10.1007/s00704-019-02966-X

532 Hassan WH, Hashim FS (2020) The effect of climate change on the maximum temperature in

533 Southwest Iraq using HadCM3 and CanESM2 modelling. SN Appl. Sci 2: 1-11.

534 https://doi.org/10.1007/s42452-020-03302-z

535 Huang J, Zhang J, Zhang Z, Xu CY, Wang B, Yao J (2011) Estimation of future precipitation

536 change in the Yangtze River basin by using statistical downscaling method. Stoch. Environ.

537 Res. Risk Assess 25: 781-792. https://doi.org/10.1007/s00477-010-0441-9

538 Kisi O, Demir V (2016) Evapotranspiration estimation using six different multi-layer 539 perceptron algorithms. Irrig. Drain. Syst. Eng 5 : 1-6. https://doi.org/10.4172/2168$540 \quad 9768.1000164$

541 Landeras G, Ortiz-Barredo A, Lopez JJ (2008) Comparison of artificial neural network models 542 and empirical and semi-empirical equations for daily reference evapotranspiration estimation 543 in the Basque Country (Northern Spain). Agric. water Manag 95: 553-565.

544 Lotfi M, Kamali GA, Meshkatee AH, Varshavian V (2020) Study on the impact of climate 545 change on evapotranspiration in west of Iran. Arab. J. Geosci. 13, 1-11. 546 https://doi.org/10.1007/s12517-020-05715-x

547 Mahmood R, Babel MS (2013) Evaluation of SDSM developed by annual and monthly sub548 models for downscaling temperature and precipitation in the Jhelum basin, Pakistan and India. 549 Theor. Appl. Climatol 113: 27-44. https://doi.org/10.1007/s00704-012-0765-0

550 Majhi B, Naidu D, Mishra AP, Satapathy SC (2020) Improved prediction of daily pan 
551 evaporation using Deep-LSTM model. Neural Comput. Appl 32: 7823-7838.

$552 \quad$ https://doi.org/10.1007/s00521-019-04127-7

553 Maqsood J, Farooque AA, Wang X, Abbas F, Acharya B, Afzaal H (2020) Contribution of $554 \quad$ climate extremes to variation in potato tuber yield in Prince Edward Island. Sustain 12: 4937. $555 \quad$ https://doi.org/10.3390/SU12124937

556 Pallant JF (2007) SPSS Survival Manual: A Step by Step Guide to Data Analysis Using SPSS 557 for Windows Version 15.

558 Randall DA, Wood RA, Bony S, Colman R, Fichefet T, Fyfe J, Kattsov V, Pitman A, Shukla 559 J, Srinivasan J, Stouffer RJ 2007. Climate models and their evaluation. In Climate Change 560 2007: The physical science basis. Contribution of Working Group I to the Fourth Assessment 561 Report of the IPCC (FAR). Cambridge University Press 589-662.

562 Ren X, Qu Z, Martins DS, Paredes P, Pereira LS (2016) Daily reference evapotranspiration for 563 hyper-arid to moist sub-humid climates in Inner Mongolia, China: I. Assessing temperature 564 methods and spatial variability. Water Resour. Manag 30: 3769-3791. 565 https://doi.org/10.1007/s11269-016-1384-9

566 Richards W, Daigle R (2011) Scenarios and guidance for adaptation to climate change and sea 567 level rise - NS and PEI municipalities. Atlantic climate adaptation solutions association.

568 Shi L, Feng P, Wang B, Li Liu D, Cleverly J, Fang Q, Yu Q (2020) Projecting potential 569 evapotranspiration change and quantifying its uncertainty under future climate scenarios: A $570 \quad$ case study in southeastern Australia. J. Hydrol 584: 124756. $571 \quad$ https://doi.org/10.1016/j.jhydrol.2020.124756

572 Statistics Canada (2020) Population growth rate, 2018/2019 and 2019/2020, Canada, provinces 573 and territories. https://www150.statcan.gc.ca/n1/daily-quotidien/200929/cg-b002-eng.htm. 
575 Sudheer KP, Gosain AK, Ramasastri KS (2003) Estimating actual evapotranspiration from

576 limited climatic data using neural computing technique. J. Irrig. Drain. Eng 129: 214-218.

577 https://doi.org/10.1061/(ASCE)0733-9437(2003)129:3(214)

578 Tabari H, Talaee PH (2013) Multilayer perceptron for reference evapotranspiration estimation

579 in a semiarid region. Neural Comput. Appl $23: 341-348$. https://doi.org/10.1007/s00521-012-

$580 \quad 0904-7$

581 Ul Shafiq M, Ramzan S, Ahmed P, Mahmood R, Dimri AP (2019) Assessment of present and 582 future climate change over Kashmir Himalayas, India. Theor. Appl. Climatol 137: 3183-3195. 583 https://doi.org/10.1007/s00704-019-02807-x

584 Van Vuuren DP, Edmonds J, Kainuma M, Riahi K, Thomson A, Hibbard K, Hurtt GC, Kram 585 T, Krey V, Lamarque JF, Masui T, Meinshausen M, Nakicenovic N, Smith SJ, Rose SK (2011) 586 The representative concentration pathways: An overview. Clim. Chan 109: 5-31. 587 https://doi.org/10.1007/s10584-011-0148-z

588 Vicente-Serrano SM, Azorin-Molina C, Sanchez-Lorenzo A, Revuelto J, López-Moreno JI, 589 González-Hidalgo JC, Moran-Tejeda E, Espejo F (2014) Reference evapotranspiration 590 variability and trends in Spain, 1961-2011. Glob. Planet. Chan 121: 26-40. 591 https://doi.org/10.1016/j.gloplacha.2014.06.005

592 Wilby RL, Dawson CW, Barrow EM (2002) SDSM - A decision support tool for the 593 assessment of regional climate change impacts. Environ. Model. Softw 17: 145-157. 594 https://doi.org/10.1016/s1364-8152(01)00060-3

595 Wilby RL, Hay LE, Gutowski WJ, Arritt RW, Takle ES, Pan Z, Leavesley GH, Clark MP 596 (2000) Hydrological responses to dynamically and statistically downscaled climate model 
output. Geophys. Res. Lett 27: 1199-1202. https://doi.org/10.1029/1999GL006078

598 Zanetti SS, Sousa EF, Oliveira VPS, Almeida FT, Bernardo S (2007) Estimating 599 evapotranspiration using artificial neural network and minimum climatological data. Irrig.

600 Drain. Syst 133: 83-89. https://doi.org/10.1061/ASCE0733-94372007133:283

601 Zhai Y, Huang G, Wang X, Zhou X, Lu C, Li Z (2019) Future projections of temperature 602 changes in Ottawa, Canada through stepwise clustered downscaling of multiple GCMs under 603 RCPs. Clim. Dyn 52: 3455-3470. https://doi.org/10.1007/s00382-018-4340-y

604 Zhang J, Zhu Y, Zhang X, Ye M, Yang J (2018) Developing a long short-term memory 605 (LSTM) based model for predicting water table depth in agricultural areas. J. Hydrol 561: 918606 929. https://doi.org/10.1016/j.jhydrol.2018.04.065

607 Zhang L.E.I, Xu Y, Meng C, Li X, Liu H, Wang C (2020) Comparison of statistical and 608 dynamic downscaling techniques in generating high-resolution temperatures in China from 609 CMIP5 GCMs. J. Appl. Meteorol. Climatol 59: 207-235. https://doi.org/10.1175/JAMC-D$610 \quad 19-0048.1$ 